
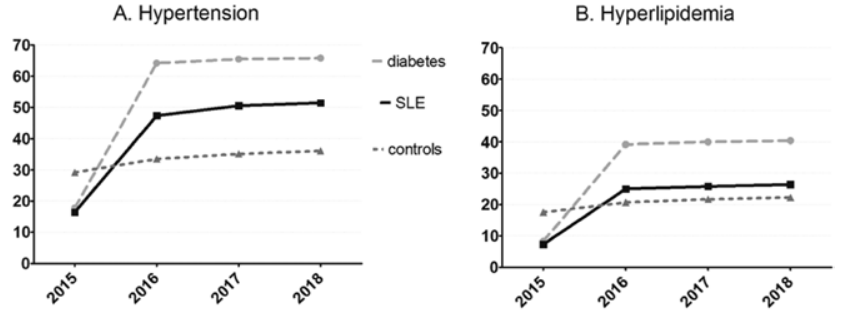

C. Depression

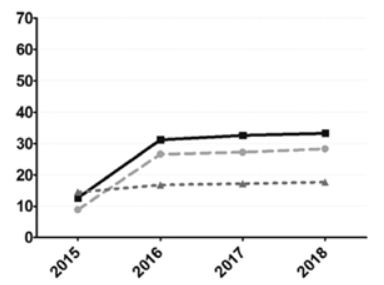

D. Osteoporosis

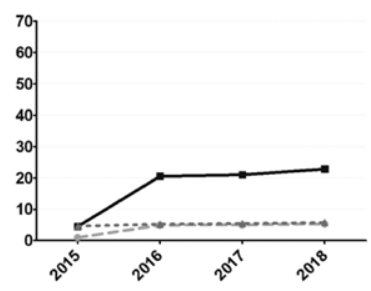

E. Osteoarthritis
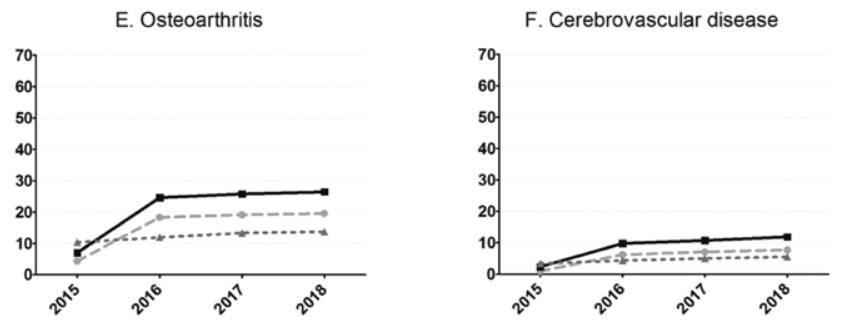

Conclusion: Cardiovascular, bone and neurologic comorbidities are frequently detected already at the time of diagnosing SLE. High numbers of medical prescriptions and hospitalization following SLE diagnosis reflect the comprehensive disease burden. Differences to controls without autoimmune disease are overestimated by detection bias.

References: Funding The study was supported by the Wolfgang Schulze Foundation of the German Rheuma-Liga

Disclosure of Interests: Katinka Albrecht: None declared, Imke Redeker: None declared, Martin Aringer Consultant of: Boehringer Ingelheim, Roche, Speakers bureau: Boehringer Ingelheim, Roche, Ursula Marschall: None declared, Angela Zink Speakers bureau: AbbVie, Amgen, BMS, Gilead, Hexal, Janssen, Lilly, MSD, Pfizer, Roche, Sanofi Aventis, UCB, Johanna Callhoff: None declared DOI: 10.1136/annrheumdis-2020-eular.991

\section{FRI0152 1 PULMONARY HYPERTENSION IN NEWLY DIAGNOSED SPANISH PATIENTS WITH SYSTEMIC LUPUS ERYTHEMATOSUS: DATA FROM THE RELES COHORT}

J. Álvarez Troncoso ${ }^{1}$, Á. Robles Marhuenda ${ }^{1}$, F. Mitjavila Villero ${ }^{2}$, F. J. García Hernández $^{3}$, A. Marín Ballvé ${ }^{4}$, A. Castro ${ }^{5}$, G. Salvador Cervelló ${ }^{6}$, E. Fonseca ${ }^{7}$, I. Perales Fraile ${ }^{8}$, G. Ruiz-Irastorza ${ }^{9}$ on behalf of GRUPO RELES Investigators, Autoimmune Diseases Study Group (GEAS). ${ }^{1}$ Hospital Universitario La Paz, Department of Internal Medicine, Madrid, Spain; ${ }^{2}$ Hospital Universitari de Bellvitge, Department of Internal Medicine, L'Hospitalet de Llobregat, Barcelona, Spain; ${ }^{3}$ Hospital Virgen del Rocío, Department of Internal Medicine, Sevilla, Spain; ${ }^{4}$ Hospital Clínico Universitario Lozano Blesa /IIS Aragón, Grupo Autoinmunidad Clínica, Department of Internal Medicine, Zaragoza, Spain; ${ }^{5}$ Hospital Universitari Sant Joan de Reus, Department of Internal Medicine, Tarragona, Spain; ${ }^{6}$ Hospital Universitario La Fe, Department of Internal Medicine, Valencia, Spain; ${ }^{7}$ Hospital de Cabueñes, Department of Internal Medicine, Gijón, Spain; ${ }^{8}$ Hospital Infanta Sofía, Department of Internal Medicine, Madrid, Spain; ${ }^{9}$ Hospital Universitario de Cruces, Unit of Autoimmune Diseases, Department of Internal Medicine, Baracaldo, Vizcaya, Spain

Background: Systemic lupus erythematosus (SLE) is a systemic autoimmune disease characterized by multiorgan involvement. Pulmonary hypertension $(\mathrm{PH})$ is an uncommon manifestation with high morbidity and mortality whose characteristics, prevalence and evolution in SLE are not completely defined.

Objectives: Using data of patients from the inception cohort Registro Español de Lupus Eritematoso Sistémico (RELES), we aimed to to identify the factors associated with pulmonary hypertension (PH) in systemic lupus erythematosus (SLE). Methods: Prospective observational study on a multicenter Spanish inception cohort. Patients with SLE, diagnosed by the American College of Rheumatology
(ACR) criteria, since January 2009, who had at least one transthoracic echocardiogram (TTE) performed were selected. Demographic data, diagnostic criteria, follow-ups, treatments and SLEDAI were analyzed.

Results: Of 289 patients diagnosed with SLE with TTE performed, 15 (5.2\%) patients were identified to have $\mathrm{PH}$. Mean age was $56,9 \pm 7,7$ years, of which $93,3 \%$ (14) were women and $80 \%$ (12) Caucasian. The ACR score at diagnosis was 4.66 . Mean SLEDAI was 15 . Only 5 patients had dyspnea the time of diagnosis. Mean pulmonary arterial systolic pressure was $49.2 \pm 5.6 \mathrm{mmHg}$. Among the $\mathrm{PH}, 4$ patients had pericarditis $(26.6 \%), 3(20 \%)$ valvulopathies (1 antiphospholipid syndrome), 1 patient pulmonary embolism and 1 shrinking lung. Multivariable analysis indicated that pericarditis (odds ratio $(O R)=2.53$ ), and valvulopathies (OR 8.96) were independently associated with the development of $\mathrm{PH}$ in SLE. Having PH was associated with older age at diagnosis $(p<0.001)$, more dyspnea $(p<0.001)$, higher ESR $(p=0.007)$, more serositis $(p<0.001)$, higher SLEDAI $(p=0.011)$, higher SLICC $(p<0.001)$, higher number of admissions $(p=0.006)$ and higher mortality $(p=0.003)$.

Conclusion: PH in SLE is a serious comorbidity with high mortality. In the RELES cohort it was associated with increased disease activity, pericarditis and valvulopathies. Performing TTE in patients with SLE may favor early diagnosis and treatment.

\section{References:}

[1] Kim JS, Kim D, Joo YB, et al. Factors associated with development and mortality of pulmonary hypertension in systemic lupus erythematosus patients. Lupus. 2018;27(11):1769-1777.

[2] Bazan IS, Mensah KA, Rudkovskaia AA, et al. Pulmonary arterial hypertension in the setting of scleroderma is different than in the setting of lupus: $A$ review. Respir Med. 2018;134:42-46.

Disclosure of Interests: Jorge Álvarez Troncoso: None declared, Ángel Robles Marhuenda: None declared, Francesca Mitjavila Villero: None declared, Francisco José García Hernández: None declared, Adela Marín Ballvé: None declared, Antoni Castro Consultant of: Actelion pharmaceuticals, GSK, MSD. Gonzalo Salvador Cervelló: None declared, Eva Fonseca: None declared, Isabel Perales Fraile: None declared, Guillermo Ruiz-Irastorza: None declared DOI: 10.1136/annrheumdis-2020-eular.4906

\section{\begin{tabular}{|l|l}
\hline FRI0153 ULTRA HIGH-RESOLUTION ULTRASOUND (UHFUS) \\
\hline
\end{tabular} OF LABIAL SALIVARY GLANDS: POTENTIAL APPLICATIONS IN PRIMARY SJÖGREN'S SYNDROME}

C. Baldini ${ }^{1}$, F. Ferro ${ }^{1}$, R. Izzetti ${ }^{1}$, S. Vitali ${ }^{1}$, S. Fonzetti ${ }^{1}$, G. Governato ${ }^{1}$,

G. Aringhieri ${ }^{1}$, E. Elefante ${ }^{1}$, M. Mosca ${ }^{1}$, V. Donati ${ }^{1}$, D. Caramella ${ }^{1}$. ${ }^{1}$ University of Pisa, Clinical and Experimental Medicine, Pisa, Italy

Background: Major salivary gland ultrasonography has an established role in diagnosis and assessment of pSS. Nowadays, however, interest is also growing in last-generation ultra high resolution ultrasound (UHFUS) transducers, which can produce frequencies up to $70 \mathrm{MHz}$ and achieve tissue resolution up to 30 $\mu \mathrm{m}$, opening up new possibilities for the study labial salivary glands (LSG).

Objectives: To investigate the usefulness of UHFUS in LSG ultrasound-guided biopsy and preoperative planning.

Methods: Consecutive patients undergoing a LSG for clinically suspected pSS were included in this study from January 2018 to December 2019. UHFUS of LSG was performed by using VEVO MD, equipped with a $70 \mathrm{MHz}$ probe, scanning first the central compartment of the inferior lip, and then both peripheral compartments. The following parameters were evaluated: distribution of the glands, parenchymal inhomogeneity (score 0-3, from normal to evident), and fibrosis. UHFUS imaging was used to help locate the LSG for the US-guided biopsy. The same expert pathologist calculated the surface area of gland sections examined, the LSG focus score (FS), the number of foci and evaluated the presence of ectopic germinal centers (GCs). Consecutive patients that had undergone a traditional LSG biopsy from December 2016 to December 2017 were included as controls. Results: We included a total of 249 patients with suspected pSS: 137 undergoing the UHFUS-guided LSGs and 112 the traditional LSG biopsy procedure. No demographic differences were observed between the two groups. No differences were also observed in the distribution of the final diagnosis. A diagnosis of pSS according the ACR 2016 criteria was made in 60/137 (43.8\%) and 36/112 $(32.1 \%)$ patients, respectively whereas a diagnosis of no-SS sicca was made in $44 / 137(32.1 \%)$ and in $43 / 112(38.4 \%)$ patients; the remaining diagnosis included secondary SS (4/137, $3 \%$ and $9 / 112,8 \%)$ and undifferentiated connective tissue disease (UCTD) $(29 / 137,21.2 \%$, and $24 / 112,21.4 \%)$. With respect to no-SS sicca controls and UCTD patients, pSS patients presented higher UHFUS inhomogeneity scores in both central and peripheral labial compartments $(p=0.001)$. There were no complications from the HUFUS-guided LSG biopsy. The mean glandular surface area obtained was significantly higher than the area obtained by traditional LSG biopsy procedure $\left(7.4 \pm 4.0 \mathrm{~mm}^{2}\right.$ vs $\left.6.3 \pm 3.7 \mathrm{~mm}^{2}, \mathrm{p}=0.02\right)$ thus facilitating the assessment of the FS. Interestingly, the latter showed a good correlation with the UHFUS inhomogeneity $\left(r=0.509^{* *}, p=0.000\right)$. 
Conclusion: UHFUS of LSG appeared feasible and sensitive in pSS, potentially offering unique advantages in LSG ultrasound-guided biopsy.

Disclosure of Interests: None declared

DOI: 10.1136/annrheumdis-2020-eular.4697

\begin{tabular}{|l|l}
\hline FRI0154 & SHOULD BE OLDER PATIENTS TESTED FOR \\
ANTIPHOSPHOLIPID ANTIBODIES? 695 CASES FROM \\
THE RETROSPECTIVE SERIES HIBISCUS
\end{tabular}

C. Belizna ${ }^{1}$, O. Latino ${ }^{2}$, L. Stojanovich ${ }^{3}$, P. Saulnier ${ }^{1,4}$, K. Devreese $^{5}$, S. Udry ${ }^{2}$, N. Stanisavljevic ${ }^{3}$, A. Djokovic ${ }^{3}$, J. Alijotas-Reig ${ }^{6}$, E. Esteve-Valverde ${ }^{6}$, R. FerrerOliveras $^{6}$, A. Tincani ${ }^{7}$, L. Andreoli ${ }^{7}$, F. Regola ${ }^{7}$, M. Limper ${ }^{8}$, A. Makatsariya ${ }^{9}$, J. Khizroeva ${ }^{9}$, V. Bitsadze ${ }^{9}$, C. Chighizola ${ }^{10}$, F. Pregnolato ${ }^{10}$, M. O. Borghi ${ }^{10}$, P. L. Meroni ${ }^{10}$ on behalf of HIBISCUS. ${ }^{1}$ University Hospital Angers, Angers, France; ${ }^{2}$ Hospital Carlos Durand, Buenos Aires, Argentina; ${ }^{3}$ University Medical Center, Belgrade, Serbia; ${ }^{4}$ Research Department Unit University Hospital Angers, France, Angers, France; ${ }^{5}$ University Hospital, Gent, Belgium; ${ }^{6}$ University Hospital, Barcelona, Spain; ${ }^{7}$ Rheumatology and Clinical Immunology Unit, University of Brescia, Brescia, Italy, Brescia, Italy; ${ }^{8}$ University Medical Center, Utrecht, Netherlands; ${ }^{9}$ Obstetrics Department, First IM Sechenov State Medical University, Moscow, Russia, Moscow, Russian Federation; ${ }^{10}$ Clinical Immunology and Rheumatology Research Department Auxologico Institute Milan, Italy, Milan, Italy

Background: Although guidelines do not recommend antiphospholipid antibodies testing after 60 yo, recent data reported late onset antiphospholipid syndrome (APS).

Objectives: To comparatively analyse the clinical, laboratory features and outcomes in 695 cases with primary APS between patients older and younger than 70 yo. Methods: we have performed an international study within the framework of the International Registry of primary APS patients treated with Hydroxychloroquine, HIBISCUS (an ongoing retrospective and prospective register launched in 2016). 28 centres from 17 countries participate. Data about late onset APS were analysed in 695 patients and were obtained from a standardized form registered in the database containing 66 items with respect to demographics, clinical and biological features.

Results: Arterial events and especially stroke represented the main initial and recurrent clinical manifestation in 40 primary APS patients older than 70 yo. There were not statistically significant differences with respect to cardiovascular risk factors between the two groups of patients. A significant male predominance, a familial APS history, a higher prevalence of triple positivity, lower complement levels, and anticardiolipin antibodies ( $\mathrm{aCL}$ ) $\lg \mathrm{A}$ isotype were found in older patients. Low anticoagulation regimens were safe and efficient, with a low relapse rate in older patients.

Conclusion: we suggest that the detection of aPL antibodies should be included into the initial screening panel tests in elderly with thrombotic events, especially arterial, in particular those with recurrent stroke and familial APS.

Our study further suggests that lower intensity anticoagulation regimens could be a therapeutic option in older APS patients, as no differences in outcomes and relapse rate were found between patients with high and low intensity anticoagulation regimens.

References:

[1] Grimaud F et al. Rheumatology. 2019;58:1006-10.

[2] Goldman-Mazur S et al. Thromb Res. 2019;176:67-73.

[3] Hirmerova J et al. 2017;36:167-73.

Disclosure of Interests: Cristina Belizna: None declared, Omar Latino: None declared, Ljudmila Stojanovich: None declared, Patrick Saulnier: None declared, Katrien Devreese: None declared, Sebastien Udry: None declared, Natasa Stanisavljevic: None declared, Aleksandra Djokovic Speakers bureau: KRKA, Astra Zeneca, Actavis, Jaume Alijotas-Reig: None declared, Enrique Esteve-Valverde: None declared, Raquel Ferrer-Oliveras: None declared, Angela Tincani: None declared, Laura Andreoli: None declared, Francesca Regola: None declared, Maarten Limper: None declared, Alexander Makatsariya: None declared, Jamilya Khizroeva: None declared, Viktoria Bitsadze: None declared, Cecilia Chighizola: None declared, Francesca Pregnolato: None declared, Maria Orietta Borghi: None declared, Pier Luigi Meroni: None declared

DOI: 10.1136/annrheumdis-2020-eular.6417

\begin{tabular}{|l|l}
\hline FRI0155 & A MULTICENTER “AT-RISK” COHORT FOR THE \\
DISCOVERY OF ENVIRONMENTAL, CLINICAL AND \\
MOLECULAR PREDICTORS FOR THE TRANSITION \\
INTO SYSTEMIC LUPUS ERYTHEMATOSUS (SLE)
\end{tabular}

C. Adamichou ${ }^{1}$, D. Nikolopoulos ${ }^{2}$, M. Nikoloudaki ${ }^{1}$, Z. Rahme ${ }^{3}$, M. Fredi ${ }^{3}$, A. Pieta ${ }^{2}$, A. Repa ${ }^{1}$, A. Parma ${ }^{4}$, E. Kalogiannaki ${ }^{1}$, N. Avgustidis ${ }^{1}$, N. Kougkas ${ }^{1}$, A. Banos ${ }^{2,5}$, A. Eskitzis ${ }^{1}$, A. Bortoluzzi ${ }^{6}$, S. Jacobsen ${ }^{7}$, P. Sidiropoulos ${ }^{1}$, E. Dermitzakis ${ }^{5,8}$, M. Mosca ${ }^{4}$, L. Inês ${ }^{9}$, L. Andreoli ${ }^{3}$, A. Tincani ${ }^{3}$, A. Fanouriakis ${ }^{2}$,
G. Bertsias ${ }^{1} .{ }^{1}$ University of Crete Medical School, Rheumatology, Iraklio, Greece; ${ }^{2}$ National and Kapodistrian University of Athens, 4th Department of Internal Medicine, Athens, Greece; ${ }^{3}$ University of Brescia, Rheumatology, Brescia, Italy; ${ }^{4}$ University of Pisa, Rheumatology, Pisa, Italy; ${ }^{5}$ Biomedical Research Foundation, Academy of Athens, Athens, Greece; ${ }^{6}$ University of Ferrara, Ferrara, Italy; ${ }^{7}$ Copenhagen University, København, Denmark; ${ }^{8}$ University of Geneva, Geneva, Switzerland; ${ }^{9}$ University of Coimbra, Coimbra, Portugal

Background: SLE onset is preceded by a preclinical phase evidenced by the presence of anti-nuclear and other autoantibodies (autoAbs), which however, have low predictive value for development of clinical SLE.

Objectives: To define the subgroup of autoAbs-positive individuals who are at high risk for progression into SLE by integrating environmental, clinical/serological, genetic and transcriptome data.

Methods: A multicenter, across five European countries, inception cohort of autoAbs-positive individuals or first-degree relatives (FDRs) of SLE patients who are monitored prospectively over five years for possible transition to SLE according to the classification criteria. Structured data collection on demographics, family and medical history, clinical (criteria and selected non-criteria manifestations) and serological parameters, use of medications, hydroxyvitamin D levels and lifestyle (tobacco, alcohol use, physical activity, adherence to Mediterranean diet). Blood samples are stored for RNA-sequencing and genotyping.

Results: A total 254 at-risk individuals (93\% women, 99\% Caucasians, aged [mean \pm standard deviation] $36 \pm 12$ years) have been included and enrolment/monitoring is still ongoing. Forty individuals (16\%) have FDR with SLE and 88 individuals (35\%) have FDR with another autoimmune disorder. The frequency of active and past use of tobacco was $28 \%$ and $20 \%$, respectively. Sedentary lifestyle (moving only for necessary chores or outdoor activity 1-2 times/week) was reported by $54 \%$ and adherence to the Mediterranean diet was low ( $3.4 \pm 2.3$, maximum score: 9$)$. At enrolment, individuals had $1.9 \pm 1.1$ ACR-1997 classification criteria, with anti-nuclear antibodies (ANA) being the most frequent $(88 \%)$, followed by synovitis $(39 \%)$, photosensitivity $(33 \%)$ and immunologic disorder (30\%) (Table 1). During follow-up of $15.2 \pm 7.2$ months, a total 15 individuals $(5.9 \%)$ have progressed into classified SLE, including cases with severe hematological and neurological disease.

Table 1. Baseline characteristics of the at-risk for SLE cohort

\begin{tabular}{lc}
\hline & $\mathbf{N}(\%)$ or mean \pm SD \\
\hline ACR 1997 classification criteria & $1.9 \pm 1.1$ \\
Malar rash & $68(27 \%)$ \\
Discoid rash & $29(11 \%)$ \\
Photosensitivity & $83(33 \%)$ \\
Mucosal ulcers & $49(19 \%)$ \\
Synovitis & $100(39 \%)$ \\
Serositis & $30(12 \%)$ \\
Renal disorder & $28(11 \%)$ \\
Neurologic disorder & $31(12 \%)$ \\
Hematologic disorder & $58(23 \%)$ \\
Immunologic disorder & $77(30 \%)$ \\
ANA & $222(88 \%)$ \\
SLICC 2012 classification criteria & $1.0 \pm 0.9$ \\
Clinical criteria & $1.3 \pm 0.9$ \\
Immunological criteria & \\
\hline
\end{tabular}

Conclusion: Among individuals with positive autoAbs or FDRs with SLE, the short-term risk for transition into clinical SLE is low. Following the study completion, clinical and lifestyle data will be combined with blood transcriptome to define a high-risk subgroup of individuals for progression into SLE.

Acknowledgments: The study is supported by the Foundation for Research in Rheumatology (FOREUM; preclin016)

Disclosure of Interests: Christina Adamichou: None declared, Dionysis Nikolopoulos: None declared, Myrto Nikoloudaki: None declared, Zahra Rahme: None declared, Micaela Fredi: None declared, Antigoni Pieta: None declared, ARGYRO REPA: None declared, Alice Parma: None declared, Eleni Kalogiannaki: None declared, Nestor Avgustidis: None declared, Nikolaos Kougkas: None declared, Aggelos Banos: None declared, Anastasios Eskitzis: None declared, Alessandra Bortoluzzi: None declared, Søren Jacobsen: None declared, Prodromos Sidiropoulos: None declared, Emmanouil Dermitzakis: None declared, Marta Mosca: None declared, Luís Inês: None declared, Laura Andreoli: None declared, Angela Tincani: None declared, Antonis Fanouriakis Paid instructor for: Paid instructor for Enorasis, Amgen, Speakers bureau: Paid speaker for Roche, Genesis Pharma, Mylan, George Bertsias Grant/research support from: GSK, Consultant of: Novartis

DOI: 10.1136/annrheumdis-2020-eular.4468 